\title{
Chapter 3 \\ Pragmatism. Practice and the possibility of progress
}

\begin{abstract}
"The ethical life belongs to human beings, living together in ever larger groups, and working out their shared lives with one another. Philosophy's task is to facilitate this working out." - P. Kitcher
\end{abstract}

\section{Cosmopolitanism as a personal way of life}

Cosmopolitanism and egalitarianism are not only theoretical normative ideals. They can become a lived practice when they are endorsed by individual agents, shape their ethos, and influence how agents feel and think, talk and act about global issues. The third essential feature of my theory of cosmopolitan responsibility is its pragmatic nature for which I take some inspiration from the rich and diverse philosophical tradition of US-American pragmatism, notably from the works of John Dewey. ${ }^{145}$ Although the inspiration is more general than systematic, the following chapter will introduce several elements of a pragmatist approach to ethics that I suggest to integrate into the proposed theory of cosmopolitan responsibility. To be clear, I do not aspire to develop a comprehensive account of pragmatic ethics, which is admittedly in itself less a coherent moral philosophical theory than a specific perspective on the means and aims of ethics. ${ }^{146}$ Neither do I propose a full pragmatist account of (global) justice. ${ }^{147}$

145 The fact that Dewey's biography shows him personally an active cosmopolitan, involved in many progressive social movements around the world, shall only be briefly mentioned here. For his engagement in Turkey, China, Mexico and elsewhere, cf. the biography by Martin (2002).Dewey himself does not particularly stress the cosmopolitan implications of his ethics himself. Nevertheless, there have been several attempts in the literature to read him as a cosmopolitan in general, as well as a valuable contributor to the project of a global ethics (Waks 2009, Hickman 2010). Particularly fruitful, in this regard, were attempts to take up Dewey's thinking in political theory and theories of international relations (Cochran 1999, Bray 2011).

146 Good overviews are provided by LaFollette (2000), Anderson (2010a), Pappas (1998), Serra (2009) and Welchman (1995).- Yet, even for a single pragmatist philosopher like Dewey, it is difficult to identify the concrete content of his ethics. As Pappas has it: "When reading Dewey [...] it is important to resist the philosophical habit of trying to find a 'system.' A better approach is to become acquainted with his moral vision. But this task is complicated by the fact that Dewey did not consolidate his ideas about ethics in a single work. He scattered his ideas throughout his many books and essays. In some cases he even presented them in a paragraph or two placed

2 OpenAccess. (C) 2020 Jan-Christoph Heilinger, published by De Gruyter. (cc) BY-NC-ND This work is licensed under the Creative Commons Attribution-NonCommercial-NoDerivatives 4.0 License. 
In a somewhat piecemeal approach then, I simply seek to present selected elements of pragmatist and neo-pragmatist reasoning about ethics which together point towards a plausible alternative to a variety of conventional philosophical thinking about the role and goals of ethics. Central to the pragmatic approach is the role of individual experience, the importance of personal habits and patterns of conduct as a way to turn considered values into justified action, a systematic method for moral inquiry that makes room for normative pluralism, and an optimistic belief in the possibility of progress in living together. These elements also shape the ethos of cosmopolitan responsibility.

Pragmatism is often met with reproach of refusing to provide a substantial normative criterion for decision making and assessment and being concerned instead simply with 'whatever works'. If true, a narrow focus on 'whatever works' would make for a very uninteresting view, particularly in ethics, since ethics should provide appropriate reasons for the normative views held and actions undertaken. While a strict 'whatever works' hence cannot constitute a worthwhile aim of the ethical project (nor of any philosophical undertaking), the reproach against pragmatism nevertheless catches well one distinctive feature of pragmatist ethics: namely that philosophical reasoning in ethics should take into account how the theoretical tools employed make a difference in practice. A central claim in pragmatism is that ideas, including norms and values, cannot prove their "truth" independently from practical implementation, i.e. they have to be put to 'work'. In the words of James: “truth happens to an idea” (James 1909, 574). Truth, on this understanding, is nothing but the successful use of ideas in practice. Pragmatism is hence concerned, first, with the acute circumstances under which certain problems appear; and, secondly, with the impact theories and ideas actually have in such circumstances, i.e., how they work with regard to overcoming or dealing with perceived problems.

In this pragmatic sense, morality is not a detached intellectual enterprise of establishing a determinate and substantive set of rules and principles to guide human behaviour, but should be understood as a collective, social undertaking, as a continuing process, an ongoing challenge to figure out how to deal best with the given problems in the context of humans living together.

almost parenthetically in the midst of a passage devoted to another philosophical topic" (Pappas 1998, 100).

147 It has been noted that the notion of justice is largely absent in Dewey's writings (Dieleman, Rondel et al. 2017). While recently some have started to address this lacuna (Talisse 2017, Rondel 2018), my own attempt to advance the project of a global political ethics can, as is explained in this chapter, draw directly from many pragmatist insights. 
This first, tentative characterisation invites a brief recapitulation of the concrete problem for which the turn toward pragmatism seems to me particularly useful. At issue in this book is, ultimately, the problem of how humans should live together under conditions of globalisation, which are currently shaped by enormous inequalities in distribution, massive asymmetries in power and influence, and persisting domination and structural injustice. In this context it is still unclear how exactly individuals should act and institutional arrangements should look like in order to allow and support good lives for all and a good living together of all. This is the massive, current ethical challenge of the ethical project. In addressing it, Kitcher, for example, foresees also a role for moral philosophy: "The ethical life belongs to human beings, living together in ever larger groups, and working out their shared lives with one another. Philosophy's task is to facilitate this working out." (Kitcher 2012, 2). I agree and my writing thus aspires to contribute to the task of figuring out how individuals should think and act in order to live well together under the de facto circumstances of cosmopolitanism.

These global circumstances generate a jointly shared sphere of interaction that can also be caputured in pragmatic perspective. For Dewey, the actual interactions between people who live together, be it in smaller or larger groups, give rise to what he calls "the public". The public is constituted by all who are in one way or another influenced or affected by the other's actions. In The Public and Its Problems, Dewey writes

\footnotetext{
We take then our point of departure from the objective fact that human acts have consequences upon others, that some of these consequences are perceived, and that their perception leads to subsequent effort to control action so as to secure some consequences and avoid others. Following this clew, we are led to remark that the consequences are of two kinds, those which affect the persons directly engaged in a transaction, and those which affect others beyond those immediately concerned. In this distinction we find the germ of the distinction between the private and the public. When indirect consequences are recognized and there is effort to regulate them, something having the traits of a state comes into existence. (Dewey 1927, 244)
}

This distinction gives a lay of the land in which problems of global justice and global ethics are embedded: the fact that some of our actions impact on others, even if this is in a mediated and indirect manner, generates a wide-ranging and inclusive field of interaction in which there is a need for individual actions (and thus their consequences) to be regulated. I am less concerned here with Dewey's notion that this brings about already something similar to "a state". The establishment of a joint interactional sphere-in which there is mutual influence, the consequences of which are perceivable, and hence at least some effort is 
made to regulate individual actions-is sufficient. Dewey further specifies "the public" by stating that it "consists of all those who are affected by the indirect consequences of transactions to such an extent that it is deemed necessary to have those consequences systematically cared for" (Dewey 1927, 245-246).

Such a definition of "the public" as unconstrained by national boundaries is of fundamental importance to my purpose here. The relevant form of a public is created by the interactions and relationships between agents; and particularly so when the impact of some agent's action on others is harmful or damaging. ${ }^{148}$ Dewey defends a universal egalitarianism when he assumes that all persons matter equally, since "other persons are selves too" and "the good is the same in quality wherever it is found" (Dewey 1922, 202). All this points to a potentially global scope of the Deweyan public-albeit one comprised of several subsets of particularly intense interaction and influence.

Dewey can plausibly be regarded as a "relational egalitarian" for the combination of his commitment to a global public, constituted by the relations and interactions between people, and his commitment to the equal moral importance of all. ${ }^{149}$ Anderson, for example, ascribes to Dewey the idea "that a free society of equals is a society of mutually accountable individuals who regulate their claims on one another according to principles that express and sustain their social equality" (Anderson 2010b, 3, fn. 4). ${ }^{150}$ And Dewey himself writes, in the context of an early defense of an Ethics of Democracy, "The true meaning of equality is synonymous with the definition of democracy [...]. It is the form of society in which every man has a chance and knows that he has it-and we may add, a chance to which no possible limits can be put, a chance which is truly infinite, the chance to become a person. Equality, in short, is the ideal of humanity; an ideal in the consciousness of which democracy lives and moves.” (Dewey 1888, 246).

148 As I argued above, in chapter two, also abstaining from certain (inter-) actions can be of moral relevance.

149 Cf. chapters one and two above.

150 Cf. Young, in a similar spirit, on the link between individual experiences with the complexities of a social life and the need for a 'democratic' engagement among equals: "We make our moral and political judgements, then, not only by taking account of one another's interests and perspectives, but also by considering the collective social processes and relationships that lie between us and which we have come to know together by discussing the world. [...] Just because social life consists of plural experiences and perspectives, a theory of communicative ethics must endorse a radically democratic conception of moral and political judgement. Normative judgement is best understood as the product of dialogue under conditions of equality and mutual respect. Ideally, the outcome of such dialogue and judgement is just and legitimate only if all the affected perspectives have a voice” (Young 1997, 59). 
Dewey's claim about the role of the ideal of democracy can also bear on the ideal of moral cosmopolitanism: democratic ideas and ideals should, he claims, translate into "a personal, an individual, way of life," which includes "the possession and continual use of certain attitudes, forming personal character and determining desire and purpose in all the relations of life. Instead of thinking of our own dispositions and habits as accommodated to certain institutions we have to learn to think of the latter as expressions, projections and extensions of habitually dominant personal attitudes" (Dewey 1939, 226). This is as important in a domestic as in the global setting. ${ }^{151}$

In the balance of this short chapter, I hope to draw attention to certain key features of the (neo-) pragmatist tradition that appear to me to be helpful with regard to the project of contributing to a theory of global ethics by developing a more nuanced understanding of moral cosmopolitanism which can serve as the core of such an ethics. Yet, all this is meant only as a modest proposal. Nothing hinges on the distinctive historic influence of the pragmatist tradition when it comes to assessing whether the arguments I develop in later parts of this book are sound.

\section{From criterial monism to pragmatic pluralism}

Before illustrating the distinctively pragmatic approach to ethics that underlies my account of a cosmopolitan ethos, it is important to sketch what could be considered the 'standard view' of ethics, and to identify some of its troublesome features that motivated the early pragmatists' efforts to define an alternative view. The features of the 'standard view' are still very widespread in modern philosophical ethics, even if they are often held more implicitly than defended explicitly. ${ }^{152}$

The core of the pragmatic criticism of the standard view in ethics is that it understands moral theories to be "about abstract structures that sort agents, actions, or outcomes into appropriate categories" (Jamieson 1991, 477). The job of the philosopher or moral theorist within this view is to "make particular moral theories explicit, to describe their universality, and to make vivid their coercive

151 Cf. also Green (2011, 61-62).

152 Among others, Kitcher has distinguished such two different "visions in normative ethics" (Kitcher 2011, 285-288), one being what I call the 'standard view,' the other the pragmatist alternative (cf. also LaFollette 2000). A similar critique to the one developped here on pragmatist terms has been suggested by Hutchings, who builds on resources from virtue ethics, feminist ethics and postmodernist traditions for her account of global ethics (Hutchings 2018). 
power" (ibid.). Often, a single basic moral principle is identified that functions as the morally relevant criterion; for example the categorical imperative or the principle of utility. Such "criterial” views establish the relevance of a particular perspective (or paradigm) for moral thinking at the cost of other morally salient aspects with the promise of a conclusive, transcendental account of morality. Such an approach to making ethical judgements can be described as top-down, or the direct application of abstract theory to concrete problems (Arras 2010): theory comes first, and then in a second step it is applied to concrete moral problems to yield justified moral judgements.

Such universalistic, criterial moral theories standardly assume-in one way or another-that their morally relevant criteria are logically prior, fixed, complete, and directly applicable (LaFollette 2000, 401). LaFollette pointedly illustrates the assumption, using utilitarianism as an example:

Although the principle of utility might be revealed through experience, its truth is thought (a) to be logically prior to experience and (b) to provide a measure for determining what is moral for all people, at all times. Moreover, this principle (c) does not need to be supplemented, and (d) can be directly applied to specific cases. (LaFollette 2000, 401)

Problems with moral theories of this criterial type are at least threefold. First, the standard view is based on de-contextual thinking, wherein moral principles are deduced from "pure" thought and under idealised circumstances, rather than developed from real world situations and plausible approaches to their amelioration. This transcendental approach relies on forms of ideal theory that are frequently rather remote from, and even alien to, the problems people face in real life. Second, the standard view does not allow for amendment or correction. Its criteria are static, and are by definition forever right and thus inflexible and never evolving. All alternative ways of reasoning are hence neglected and excluded as being morally irrelevant. But if there remains, as there does, always the possibility that a theory has it partly or wholly wrong (falsifiability), yet amendments and corrections are ruled out by it, these theories reveal themselves to inhabit the realm of dogmatic absolutist ideological thinking. Third, theories of the standard view type are (most often) incapable of applying their theoretical insights to real world situations in a way that actually helps agents to solve the moral problems at hand. Instead, a moral method that is both intellectually and practically responsible should not rely on a monistic standard of moral judgment but integrate the complexity of the initial challenge into the moral method.

In addition to these fundamental internal problems that plague all variants of the standard view, the incommensurability of competing criterial views causes even more problems for such theories. What reason could one provide to adhere 
to only one or the other of say deontology and consequentialism, for example? Should one not aspire to put the different available tools to use when it comes to understanding the moral complexities of right and wrong?

Dewey pointedly summarises the net effect of these objections against standard moral theory and starts to identify an alternatie approach:

Moral theory cannot emerge when there is positive belief as to what is right and what is wrong, for then there is no occasion for reflection. It emerges when men are confronted with situations in which different desires promise opposed goods and in which incompatible courses of action seem to be morally justified. Only such a conflict of good ends and of standards and rules for right and wrong calls forth personal inquiry into the bases of morals. (Dewey and Tufts 1932, 164)

Dewey here embeds moral theorising in concrete circumstances in which agents, confronted with challenges in their own personal experience, have to make up their minds about what to do. Applying one single type of moral consideration, as stipulated by all the standard moral theories, shuts out entirely the insights offered by the others. From a pragmatic ethical perspective, such thinking is too narrow, too constrained to single criteria assessment, in order to be of any actual use in the making of moral evaluations in response to complex moral problems. Because of their complexity, the moral challenges almost invariably have different salient facets so that only a plurality of normative perspectives will be able to capture them. ${ }^{153}$

\section{Elements of a pragmatic ethics}

In the following section I point out four key elements of a pragmatic ethics, as suggested in the writings of Dewey: the role of individual experience, a pragmatic focus on acts and habits, a distinctive pragmatic method of inquiry and a belief in the possibility of progress.

(1) The role of individual experience. The "ordinary experience" of people lies at the centre of Dewey's philosophy (cf. Jung 2014). Experiences are an anthro-

153 The task for pragmatists consists not in integrating alternative criterial views into one which is considered to be fundamental, as it is undertaken in the attempts to "consequentialise" moral theories (Portmore 2007) or to stipulate a "threshold deontology" (Alexander 2010). Such approaches retain their distinctive theoretical affiliation to consequentialism or deontology respectively. From a pragmatic perspective the different types of moral reasons should, however, be considered as genuinely different, "independent factors" in morality (Dewey 1930), requiring thus for a genuine plurality in normative perspectives. 
pological universal and as such fundamental to the human existence. Experience is the bridge between individual persons and the world around them. In Experience and Nature, Dewey analyses in great detail the intricate relationship between mind and world, and shows the relevance of experience in many dimensions of human lives-such as in art, in science, and in society (Dewey 1925). Dewey's notion of "experience" is immensely rich and in the present context I can only shed some light on the role of experience in the realm of human action. Starting from the experience of people matters in several different ways for the present exploration of cosmopolitan responsibility. The complex experience of deprivation, disadvantage, oppression, etc. lies at the origin of what causes moral concern; the experience of irritation and uncertainty about how to respond to such triggers of moral concern shapes the situation of all those who become aware of it and could be doing something about it. Concretely, according to Dewey, the trigger for doing ethics is the experience of conflict, of "being torn between two duties," such as of having to "make a choice between competing moral loyalties and convictions," often because of a conflict between “incompatible values" (Dewey and Tufts 1932, 165). This distinctive moral experience is initially characterised by uncertainty and irritation, it disrupts the usual orientation guiding an agent's habitual conduct, and thereby, for Dewey, calls for moral "inquiry". On the role of moral theory with regard to the experience of conflicts, Dewey writes:

Moral theory can (i) generalize the types of moral conflicts which arise, thus enabling a perplexed and doubtful individual to clarify his own particular problem by placing it in a larger context; it can (ii) state the leading ways in which such problems have been intellectually dealt with by those who have thought upon such matters; it can (iii) render personal reflection more systematic and enlightened, suggesting alternatives that might otherwise be overlooked, and stimulating greater consistency in judgment. (Dewey and Tufts 1932, 166)

It is important to stress that, for Dewey, the experiences that call for moral analysis are ordinary experiences of agents going about their lives, affected by some state of affairs (Pappas 1998, 102-104, Jung 2014). Dewey further stipulates that the means for dealing with identified problems can also be found with the help of such ordinary experience: the three abilities of moral theories quoted above do not result from esoteric expert knowledge and competencies; rather, they are based in the ordinary capacities of ordinary people in ordinary circumstances. ${ }^{154}$ Dewey argues that within an appropriate institutional framework, ordina-

154 Kitcher has, following Dewey, questioned the need for or existence special ethical expertise 
ry citizens (equipped with qualitative resources stemming from their experiences) are fully capable of deliberation about complex moral and social issues. ${ }^{155}$

(2) Acts and habits. Moral action is only rarely the result of abstract rational deliberation; most often, it is embedded in collective as well as individual habits, which are mostly pre-conscious. This is not meant to downplay the role of reflexivity and reason, but its importance for most of an agent's (moral) actions must not be overestimated. For Dewey, reason standardly does not precede moral action but reason is only deployed in problematic situations to help shape the formation of new, intelligent (as opposed to unreflected) conduct that may turn into habit over time.

Consequently, a pragmatic ethics focusses generally much less on single acts and more on patterns of action, which are called habits (Dewey 1922). Habits are dispositions to respond to certain stimuli in a specific way and most often our acts, no matter whether they are of a particular moral quality or take place outside of the moral realm, are shaped by habits. These habits mirror our commitments as well as the expectations of our social environment. The important insight underlying the focus on habit is that habitual action is executed in a stable way and with little, if any, reflective effort. We just act and do not have to engage in time- and energy-consuming reflection before we do so. Habits shape our conduct as long as they are not perceived to be problematic, but in some situations agents start to experience frictions and the formerly unquestioned patterns of behaviour fail to satisfy. Here, a reconsideration and restructuring of one's habits becomes necessary-not only a one time execution of a different type of action. ${ }^{156}$

Thus, the central question of pragmatic ethics is not the narrow 'what action should I take?' but 'what habit is appropriate for addressing problems of this type, how can it be developed, and how can it be incorporated as the stable future of conduct?' (cf. Hildebrand 2008, 68). Analysing a concrete, single challenge about what to do in a given situation only serves as a proxy for addressing a general problem. And if the solution to the problem at hand is found and successfully enacted, this counts in favour of acting alike in similar situations. Here is an example: Should one come to the conclusion that it is morally demanded to donate some percentage of one's disposable income to charity, it is not enough

that goes beyond what "ordinary" citizens can do guided by an intelligent method of ethical inquiry (Kitcher 2001, 2011).

155 Cf. Cochran who explains how for Dewey "a public is an instrument through which problem-solving is socially coordinated” (Cochran 2010, 325).

156 In this regard, Dewey agrees with Aristotle who, in Nicomachean Ethics, argued that "one swallow does not make a summer" (Aristotle NE, 1098a17). 
to donate once. For a single such act does not sufficiently address the relevant ethical challenge, which deals with patterns of (inter-) action. Ethics for Dewey is not about one-off choices, but about forming stable character traits, dispositions to act in a certain way, for the origin of many of the social problems-also and particularly in the context of global structural injustice-do not result from single acts but from repeated acts and patterns of action that result from morally problematic habits. Since the single individual act alone is too meagre to bring about lasting change, only change in the habits can. ${ }^{157}$

This point demonstrates how a pragmatist ethics takes an important interest in the entire character of the person who is acting, rather than in individual acts alone. Pragmatists emphasise the importance of persons acting as the person they want to become also in the light of their considered moral judgements. As Dewey has it:

it is proper to say that in choosing this object rather than that, one is in reality choosing what kind of person or self one is going to be. Superficially, the deliberation which terminates in choice is concerned with weighing the values of particular ends. Below the surface, it is a process of discovering what sort of being a person most wants to become. (Dewey and Tufts 1932, 287)

Concretely, acts are hence on the one hand voluntary consequences of knowing and choosing, and, as such, are also contributions to and expressions of a rather stable yet constantly evolving character (Dewey and Tufts 1932, 166, 167). In this light, even seemingly trivial acts-the everyday acts we perform without any explicit decisions-matter a great deal morally, since they result from character. Dewey specifies: "If we omitted from our estimate of moral character all the deeds done in the performance of daily tasks, satisfaction of recurrent needs, meeting of responsibilities, each slight perhaps in itself but enormous in mass, morality would be a weak and sickly thing indeed." Hence: "Such acts, non-moral in isolation, derive moral significance from the ends to which they lead" (Dewey and Tufts 1932, 168).

Generally, the pragmatist perspective thus places significant weight on the relatively stable dispositions of people to respond in certain situations with a specific sort of action. Identifying and then cultivating the right kind of disposition-also through intelligent structuring of the social and factual environment

157 "Our moral measure for estimating any existing arrangement or any proposed reform is its effect upon impulse and habits. Does it liberate or suppress, ossify or render flexible, divide or unify interest?" (Dewey 1922, 202). 
of an agent or a group in order to support the considered habit-is an important goal of pragmatic ethics.

(3) Method of inquiry. In order to address a problem, to find out how to act and which habits to form, Dewey advocates a pluralist method of inquiry. This method, that is applicable also to the realm of ethics, was originally developed to analyse and guide the process of solving problems in the context of the sciences (Dewey 1938, 105-122). Inquiry is for Dewey, a "rule governed activity-an activity of developing hypotheses, predictions, and explanations; of assessing what is to count as evidence for or against a hypothesis or prediction; of deciding which explanations should be adopted and acted upon" (Misak 2013, 129).

What are the steps of this sort of-moral-inquiry for Dewey? First, an agent experiences some general unease in a situation, a diffuse irritation, without being able to concretely delineate the source of that feeling. The second step consists in attempting to identify and specify exactly the concrete problem that is so vexing. This step is particularly important, since often it is unclear what exactly was at the origin of the initial experience of unease and irritation. This second step is for Dewey already experimental, insofar as it is by definition tentative, always open to further revision. The third step consists in considering one or several possible solutions that may promise to overcome the initial confusion. After this heuristic step, the next one consists in experimentally imagining the implications of the candidate solutions by predicting and comparing their different multidimensional consequences and implications. This is the point at which Dewey proposes to use conventional moral philosophical principles: He acknowledges that these principles and rules contain important ethical knowledge that should be taken into consideration when it comes to anticipating the implications of certain acts. It is only the last, fifth step, that leads to actual action performed by the deliberating agent. Action, however, is also experimental and as such provisional. Only after acting does it become possible to assess the factual consequences and implications of an act. The experiences gained by actual action become, in turn, crucial for orienting future actions in analogous circumstances. If such actions are positively assessed, they may as a result contribute to the formation of a helpful habit.

To locate vexing problems and identify (moral) conflicts, it is essential to be able to identify and to name the respective values that may clash. Interestingly, as I pointed out, the existing moral principles can function here as heuristic tools in the moral inquiry, even for pragmatists. However, the "all too human love of certainty" (Dewey 1922, 242) should not lead to the isolation of principles from empirical investigations which acknowledge the contingency of concrete 
situations. For pragmatists, principles are only indispensable empirical generalisations in need of a constant readjustment to changing conditions. ${ }^{158}$

This is only the roughest sketch of what Dewey has spelled out in his Logic and I will not discuss it further. ${ }^{159}$ It remains simply to be stated that much of the work I will undertake in later chapters is best understood as contributing to the second and third steps of Dewey's pragmatic moral method: I attempt to locate the problem, and then to reveal the conflicting values that gave rise to the initially diffuse experience of irritation, the "healthy dissatisfaction with the familiar," as Nagel has called it (Nagel 1991, 8).

(4) The possibility of progress. I would like to conclude this brief introduction to pragmatic ethics with a word on the role of ideals and ends. In pragmatism, and particularly in Dewey's version, one finds a sophisticated account of meliorism, perfectionism and progress. The fundamental idea of pragmatic progress, however, is not one of teleological progress where humanity would constantly get closer to some fixed ideal end state. Instead, progress is understood in pragmatic terms: it consists in (evolutionary, not necessarily revolutionary) incremental improvements of the human capacities to live together by overcoming limitations and problems. This can occur in the form of progress in our abilities to reason about the relevant challenges at hand and, of cours, importantly also of progress 'in practice', in the form of improved individual behaviour or political and institutional reform. Pragmatic progress hence does not have to be understood as progress to some ideal, but as progress from an imperfect and problematic status quo (Kitcher 2011, 288, Kitcher 2016). ${ }^{160}$

For its belief in the possibility of achieving meaningful progress, pragmatism can also be called a "philosophy of hope." It trusts that thoughtful inquiry and the joint search for solutions in a cooperative, multi-perspective effort can actually help make things better (Rondel 2018, xii). Defending the possibility of progress in this sense amounts to the optimistic assumption that solutions to social problems can eventually be found, despite the fact that currently available

158 Cf. also Hildebrand: "Dewey promotes the capacity of pragmatic moral inquiry to sort out the nature of a problem and its possible solutions. Inquiry also has the ability to reconsider and reconstruct even the moral values and ends at stake, questioning the purposes people use to direct their conduct, and why such purposes are good [...]. Moral inquiry not only discovers morality, it makes it" (Hildebrand 2008, 79).

159 But cf. also Hildebrand (2008, 53-58) and Heilinger (2016a, 155-158) for a more detailed presentation. For a critical take on the transfer of Dewey's general method of inquiry to the field of ethics, cf. Grimm (2010, 120).

160 Sen, for example, has distinguished in a similar way his own "comparative," "non-ideal" approach to justice from Rawls’s "transcendental," "ideal” approach (Sen 2009). 
patterns of thinking and action fall short of providing them. The rejection of both the possibility of, and the need for, perfect, complete, converging and final answers-an imaginary illusion according to Dewey and his followers-is what permits this confidence in the never-ending search for stepwise improvements. ${ }^{161}$

\section{The role of philosophy}

With regard to the present problems of global injustice and global inequality, what is the role of philosophy? Mightn't it be just plainly absurd to turn to philosophers for answers to such urgent and pressing ethical questions, and for solutions to the unknown challenges that lay ahead? In a sense, it is hard to disagree with such a suggestion, for several reasons. First, philosophy is not directly concerned with practical solutions to concrete problems. It would be folly to turn to a philosopher qua philosopher in order to identify what exactly should be done by whom, for example, to fight food shortages or drought and starvation in a particular region of the world. Philosophers have few skills related to such matters; vast amounts of empirical knowledge are needed that they generally do not possess. Secondly, it would be similarly absurd to turn to philosophers alone with an expectation of receiving conclusive answers even to the conceptual theoretical questions (such as about how responsibility should be distributed or which social and political institutions should generally exist on the global level) in which philosophers do specialise, and for which they do possess pertinent skills, or to expect philosophy to decree solutions to acute chal-

161 I find these ideas helpfully spelled out in Moody-Adams's work on The Idea of Moral Progress which also stands in a pragmatist tradition (Moody-Adams 1999). She distinguishes between two forms of moral progress, one being moral progress "in belief" the other moral progress "in practices". The former consists in a deepened understanding of particular moral concepts, such as equality or justice; the latter consists in bringing such newly deepened moral understanding to influence individual behaviour or shape social institutions. In both cases, as Moody-Adams points out, progress is local, i.e. it always proceeds by departing from and improving upon a given status quo. The willingness and ability for critical self-scrutiny of numbers of individuals is a condition sine qua non for actual progress in practice, yet, on her view, academic philosophy and progress "in beliefs" alone will only have a very limited impact here. Even the important "advocacy of engaged moral inquirers" who put to use "the richness and complexity of their conceptions of rationality and rational persuasion", can be successful only if the "main obstacle to moral progress in social practices" is overcome: the tendency to "widespread affected ignorance of what can and should already be known". Yet, such self-scrutiny in an examined life is frequently avoided, particularly if people "expect it to yield insights that [they] are not prepared to obey" (180). 
lenges. Here, a broader cooperation involving others-politicians, political and social scientists, and the public-is needed.

Nevertheless, philosophers can and should play a distinctive role in the context of cosmopolitan and other ethical challenges. But not for their specific ethical knowledge, nor for their ability to provide answers and solutions. Instead, the role of philosophy is more modest. For Kitcher-and others, including Socrates-philosophy should be understood to provide a form of dialectic midwifery:

Philosophers can make proposals, attempting to facilitate the conversation that would deliver answers. [...] The most obvious forms of philosophical midwifery consist in proposing topics for consideration (places on our common vessel where planks might deserve attention) and suggestions about those topics (specific ways of rearranging the timber in those places). (Kitcher 2011, 370)

The allusion to Otto Neurath's comparison of the epistemological challenge of improving knowledge with sailors constantly rebuilding the vessel on which they sail, underlines the anti-foundational views of pragmatism: the constructive role of philosophers lies primarily in a careful contribution to identifying worthwhile topics and facilitation of processes for discussing them. Prior ethical knowledge can help here, but it is not on the grounds of such ethical knowledge that answers to new challenges will be found.

The role of philosophy as midwifery hence consists mostly in bringing certain ideas into the conversation, in explaining, exploring, developing, and nurturing them, so that they matter for ongoing challenges and debates and are alive and available to be put to use when the time is ripe.

Implicit in understanding philosophy as dialectic midwifery is the view that philosophy is no single man or woman's work, but a joint undertaking, a neverending pursuit to improve the status quo. What is necessary to deal appropriately with the challenges at hand is a coordinated and socially embedded approach. Philosophers contribute to it, but philosophers alone are in no way able or expected to provide definitive solutions. Progress can only occur in incremental steps, and, if it takes place at all, that will be because certain ideas and solutions gain broad acceptance: truth then, to quote James again, happens to an idea (James 1909, 574). Such a pursuit, to improve the human lot, is not an elitist project, but an inclusive and collaborative one involving all, and all on equal terms. Intelligence, in a pragmatic understanding, is not a feature of individuals but a cooperative praxis. If there are intelligent solutions to problems, they cannot but be found experimentally and cooperatively. Prior established knowledge alone, be it philosophical or scientific, is insufficient.

It is in this spirit that I will pursue my reasoning in this book. Central ideasequality, impartiality, rights, and responsibility-are here understood as tools for 
tackling the problems of a cosmopolitan scope. The minor contribution I hope to make to larger related debates will consist of scrutinising philosophical ideas in order to assess their meaning and relevance in the context of a global ethics. If these ideas are helpful, and if they gain somy acceptance among those affect$\mathrm{ed}^{162}$ by the problems at hand, they hold the potential to inform choices and motivate action, both in individual agents and in collectives. They are thus presented here as potential part of the larger project of finding better ways for humans to live together.

This short chapter was meant to provide an explanation for how I came to hold some of the views underlying the reasoning in the following chapters, namely the views that morality is an ongoing, collective social undertaking in which the experiences of all individuals matter and in which all those who are affected should have an equal say in the matter; that attempting to find solutions for contemporary challenges of global justice and global ethics will require a plurality of moral standards, since only such a philosophical buffet will be sufficient to capture the many ethical dimensions of the many complex social problems at issue; that moral progress, in the sense of an improved social practice, is actually possible, most likely as incremental progress that builds upon actual experiences both positive and negative and a better understanding of the normative concepts employed; and that the progressive change will be advanced by people coming jointly to hold certain views and to endorse a certain type of ethos that promotes coordinated, collective action and institutional, systemic change. Furthermore, acting together can function as an external social scaffold which promotes and supports the newly acquired, intelligent habits by ultimately taking the psychological burden of acting in unusual ways from the shoulders of individual agents.

On a pragmatic account it is not necessary to spell out how an ideal world would look like or to provide principles that, if respected, would make the world perfectly just. But it is necessary and possible to identify instances in which the lives of many people are hindered by removable, social obstacles that prevent them from pursuing their lives. Domination and exclusion from participating in the social processes that influence their lives are among them. Here, a change in the habits of the more powerful, whose behaviour, even if without malevolent intent, frequently is at the origin of such social exclusion and domination, is urgently needed. A pragmatic ethics can hint towards changes in acts and habits of individuals, and subsequently also towards social reform, that would count as

162 In the present context of our globalised world, arguably all are affected in one way or the other, as agents, patients, disadvantaged or advantaged etc. 
progressive insofar as more people will be enabled to live as equals in the global order.

This chapter has introduced a pragmatic perspective as the third central characteristic of my proposed theory of cosmopolitan responsibility. Conceiving of humans as citizens of the world that morally ought to relate to and interact with one another as moral equals is not primarily a theoretical exercise, but has a distinctively practical side to it. This side can be captured well from a pragmatic perspective: the normative commitments we have, plural as they may be, should support the living together of all humans by shaping also individual habits and patterns of action. Without an ambition to discover moral truth, but in search of solutions to practical problems that appear in the living together of humans, the pragmatic side of cosmopolitan responsibility offers guidance for action and the formation of habits, and points towards the need and the possibility to make cosmopolitanism a personal way of life. 